\title{
Making Museums Useful
}

\author{
What an Active Curator Can do for a Small Collection
}

By Harlan I. Smith, Geological Survey, Ottawa

F•r many years we have all heard an almost constant complaint from museum curators and others interested in museums, that there was not sufficient money available for the purchase of specimens, the erection of the desired building, and the building of cases. It is true desired building, and the building of cases. It is true this complaint was not always, though of ten, made as a
sort of apology for the lack of arrangement and labelling, the presence of dirt, and the failure of the museum to be very useful to the community, or even interesting to the average visitor. Some museums spend thousands of dollars for specimens annually for many years in succession, while their exhibition halls lack sufficient labels f all kinds, and especilly the general divisional labels and case labels which are among the first needed to make a museum useful to the public. It were better to buy a 5 cent book to read. After all, a museum may better do without many specimens than to be lacking in the most essential labels. One specimen such as a diamond or elephant may not only cost more than thousands of equally instructive specimens, such as a piece of coal or a kernel of corn, but will use up more of a museum's funds than would be needed to completely label a large part of a great discussing what color, and weight of cardboard or other material will be used for labels, that many years pass before any exhibit is adequately labelled, whereas it would be better to label it with written or typewritten labels on any kind of paper, so that the present generation may get useful services from the exhibit, and to replace these tentative labels whenever a better lind has been found. In this way contemporaneous gerations may derive th this way contemporane wich under the usual beneft from th ing method is lost to them through providing for futur generations. Personally, I doubt if those who follow these methods will deliver the benefits promised.

Waiting for a fire-proof or permanent or larger building is certainly a waste of time. I once knew of a professor who complained that he could not teach a number of interested students because he had no class room, but I believe I can recall hearing of certain great teachers of antiquity, who taught their disciples by the roadside, without either class room or place to lay their side, without either class room or place to lay their
heads, and this idea also applies to museums, for after heads, and this idea also applies to museums, for after
all, the whole outdoors is the best museum. A corner in every school-house may be a museum; a nook in ever board of trade building may serve the same purpose; even the Sunday school room may have its little museum. Much may be learned in both churches and saloons. cheap inflammable building may be a more useful museum building than a fire-proof structure costing millions. In a filling it would not be millions. In ayed labels, pictures, maps and books illustrated by such cheap and common specimens as elm leaves, squash seeds, broken pebbles, English sparrows, mice, and the skull of a dog. A museum of such specimens accompanied by appropriate labels, books, maps, pictures and models, might

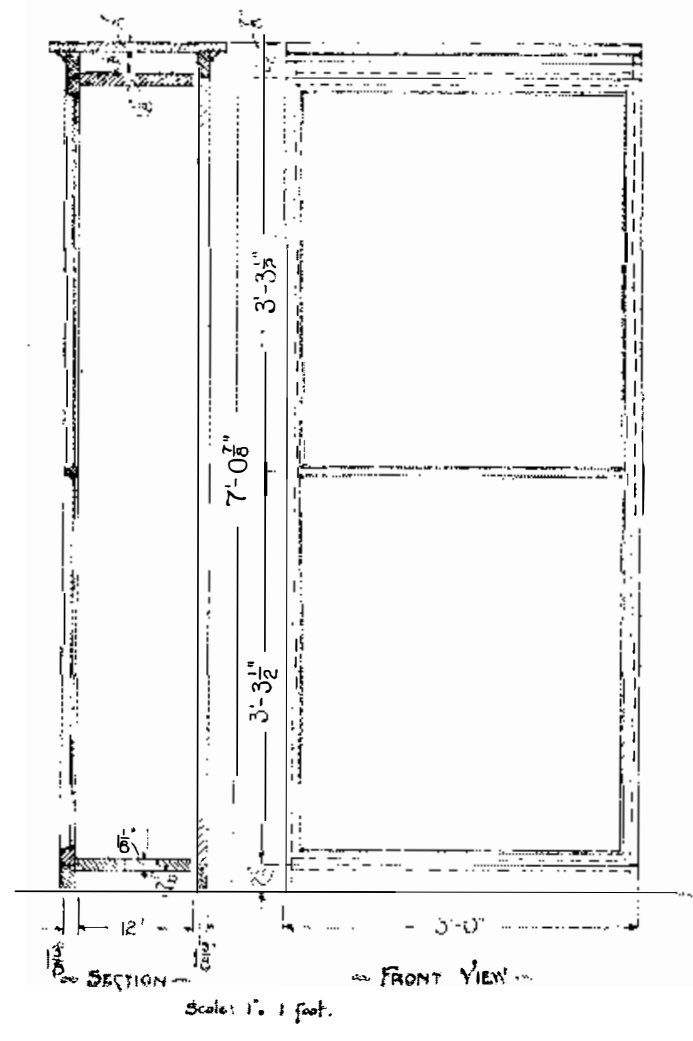

Plans for a cheap case. easily be of more service to a community than some existing museums costing say ten times as much.

Cases in which to put specimens delay curators not months but years. First there is the discussion as to what kind of a case and how to make it dust proof what the material, and the color of the background. In this way, while waiting for cases, years go by. People who would use the museum grow old and die. Children who have time in their receptive condition of mind to profit most in the museum grow up and have their time otherwise occupied. As a matter of fact, all these people could have gotten the maximum amount of benefit from the museum, had the specimens been exhibited without any floor, or even out in the big out-door world, had there been sufficient and appropriate labelling.

No doubt the background should be carefully considered, and that certain colors are better than others. Perhaps the relationship of colors or general harmony and the relationship of light and a subdued quietness of color are of extreme importance, but visitors in a museum where the cases were entirely white have been interested and obtained usefulinformation some time before noticing whether the cases were white or black.

The museum of the Natural History Society of New Brunswick, located at St. John, has a comparatively small amount of money to spend each year, and its curator has not had the great amount of university education and travel enjoyed by some curators of larger and richer museums. In this his museum is perhaps fortunate, for in so far as his funds permit he is actually putting in force some of the most up-to-date museum methods in poor building and miserable cases, yet he carries on field research, conducts a lecture course for adults and one for school children, giving two lectures per week during the school season, takes out large parties of young people to.investigate and study in the field, issues some publica-

tions, identifies material collected by school children and sent to him by their teachers, and provides the teachers of the schools with nature study leaflets suggested by the objects sent within 24 hours of their receipt.

Every fall when the Canadian Pacific Railway supplies two cars filled with exhibits under the auspices of the provincial government of New Brunswick, to be drawn over its lines and side tracked for a few hours at each station where an audience may be had, this live curator accompanies the train. One of the cars usually contains exhibits of pigs, chickens and other live stock; the other exhibits relating to agriculture, such as bees, nursery trees, creem the of the province. Our curator friend installs material from his museum, supplemented by specimens collected for the purpose. These specimens show such things as birds which benefit the farmer's crops, insects which damage them, and drawings which he hastily makes with cheap materials, but which may be fastened up around the walls of the car or held up while he lectures to the rural audiences on things which will make their work more successful not only to themselves but to their province, and which will make their lives more interesting and pleasant while they are at work. No cold blooded corporation like the Canadian Pacific Railway would furnish a two-car train, man it and haul it for about a month each year, did they not believe it would make the people who visit it more prosperous, so that they might spend more money in shipping freight and traveling on the railroad. $\mathrm{He}$ has had an ordinary carpenter remodel some of the antiquated cases cutting off the mode some the antiquated cases, outting off the portion to the amount of glass, and as fast as his funds permit, he is carrying out this scheme throughout the museum. But more interesting to us in the present connection is the cheapness of the cases which he has had built as a beginning towards those which he in-
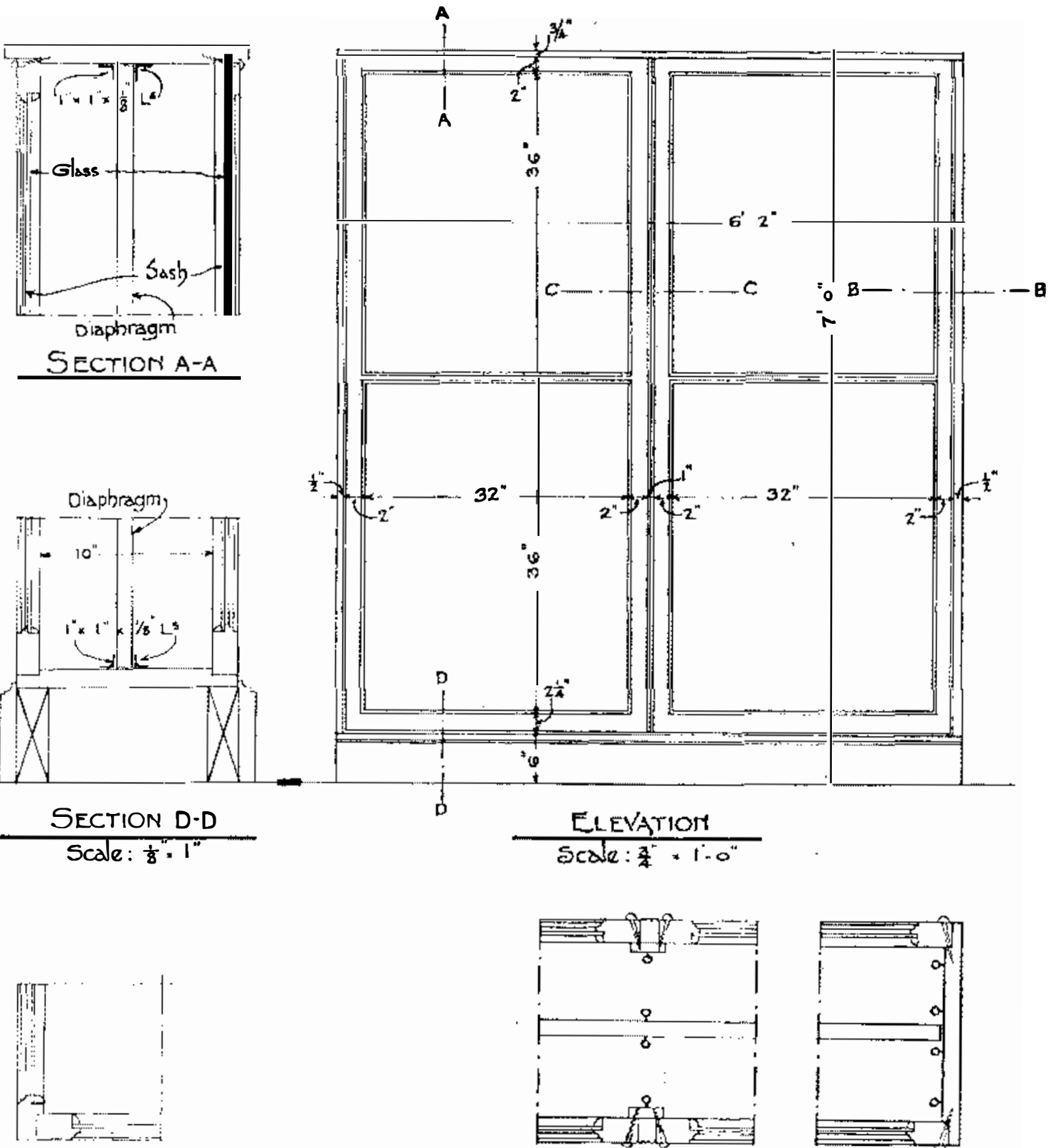

PLAN OF CORNER OF A CASE WHERE
GLASS KND IO DESIRED

SECTION B-B 
tends to have throughout the museum for the housing of instructive and useful exhibits, his idea being that while these cases are not all he would desire, still they serve the purpose so that the public, both old and young, both scientist and layman, may derive benefits from the both scientist and layman, may derive benefits from the
museum until such time as he has secured funds for ideal cases.

With this inspiration and having in the Rocky Mountains Museum need to build at least one case and install it within three weeks, I designed a cheap case for small museum or a museum having small funds.

Any ordinary house carpenter can make such a case at an extremely low cost. The materials may be obtained wherever window sashes are to be had. All the woodwork may be cut to sizes at the local mill, and this is especially desirable where a large number of cases is especially desirable where a large number of cases
are to be made, as it will save much of the expense of the are to be made,

carpenter work.

The kind of wood and molding may be varied according to what is cheapest and most easily obtainable, choose that which is simple, dignified and will not gather dust. It may be desirable to let the size of the glass panels and even of the case depend somewhat on the size of glass that can be obtained.

The advocating of a cheap case, its manufacture, installation and use, in no way militates against advocating the best and most expensive cases on the market, but on the contrary paves the way for them. The museum that waits to be useful until it can have cases costing many hundreds of dollars each will probably wait a long time for financial support. The museum that teaches and otherwise becomes useful to the public with clean, neat, though cheap cases, will gain the sound with clean, neat, though cheap cases, will gain the sound financial support which it deserves, at least as soon
as the present generation of children grow to positions as the present
of authority.

of authority.
One form and size of this case is practically a simple box 5 feet wide over all, with a window sash screwed on as a cover. The sides of the case may be $7 / 8$ stuff, 1 foot wide and 7 feet high. The top and bottom of the same stuff 1 foot wide is set in about 3 inches more or less from the ends of the sides. These four boards constitute the box frame without front or back. A piece $2 \frac{1}{2}$ inches wide is nailed across from side to side piece $21 / 2$ inches wide is nailed across from side to side at the top and bottom of both front and back to strengththe top and bottom of the case; the lower one also serves as a support upon which the lower edge of the glass front and glass or wooden back frames may rest. Thi $21 / 2$ inch strip only partly covers the edge of the top and bottom, so that the screws holding the front and back may be screwed into the top and bottom, but also so that there may be no crack or space left at the outsid of the top and bottom of the case. A kicking molding may then be put across at the bottom, both front and may then be put across at the bottom, both front and case, as this would prevent several cases being place (close together) end to end. In short, the ends of the case should be flush. A board is next put over the top of the case to keep dust and rubbish from gathering in the space outside of the case top, and to give the case finish. This board should project an inch or two in front and behind, but as in the case of the kickboard should not extend beyond the ends of the case. A molding may be placed below this top in the corner between it and the $2 \frac{1}{2}$ inch strip across the top of the front of the case according to taste. The general label may then be fastened on this molding, on the $21 / 2$ inch strip, or from the cover of the case to the $2 \frac{1}{2}$ inch strip. In fact one purpose for having the case extend above the top of the exhibition space, that is above the top of the glass sash, is to provide this space for a case label. On the other hand a case label may be painted directly on the other hand a case label may

The front of the case is made of a simple window
The $1 / 2$ inch strip or the sash. sash, such as may be obtained in any town where a sash and door factory exists, or for that matter where house are built. It is fastened with round headed screws engaging the edge of the sides and top of the case, the frame resting upon the $2 \frac{1}{2}$ inch strip across the lower part of the ease. By screwing the frame on, it is not part of the case. By screwing the frame on, it is not necessary to go to the expense of hinges and locks. The
screw holes may be soapped, waxed, or metal screw sockets may be used if it seems desirable to go to that expense. A screwdriver serves as a key. Moreover, by drawing the screws tight, the case may be made as near dust proof as is necessary in a small museum. In fact much more tuss is made about dust-proof cases and about getting fine cases than about using them after they are obtained. A little attention given to wiping out cases, cleaning specimens and looking to the upkeep of the specimens in most cases would be cheaper and quicker than giving so much attention to dust and quicker than giving so much attention to dust and
insect proof eases. Moreover, going over the specimens insect proof cases. Moreover, going over the specimen hardly fail to note the lack of order and labels, and many things, which he could then do to improve the usefulness of his exhibit. However, cotton tape or wicking set in a plained groove may be added to exclude dust if

The glass should be in the largest pieces obtainable up to the full size of the frame, and where more than one piece of glass is required preference should be given to running the mullions horizontally so that they may the more often fall opposite a horizontal shelf edge in stead of vertically across the line of vision. It is hardly necessary to say that the glass should be of the best quality which the museum can afford, and certainly should be free from blobs and other blemishes. If it is sufficiently heavy, there will be no need of disfiguring signs requesting visitors not to lean on the glass.

Shelves may be cut about $1 / 8$ of an inch shorter so that they may be moved easily and may rest upon round headed screws or still better on screw eyes turned horizontally, one at each corner of the shelf. When it horizontally, one at each corner of the shelf. When it
is necessary to raise or lower the shelf these screws are easily changed and the holes may be puttied up and touched with color, although if left they will no mor disfigure the case than the ordinary ratchets used for holding shelves at various heights. The case may be stained or painted with a dull finish, certainly not a very glossy varnish, perhaps preferably with a thin wash, glossy varnish, perhaps preferably with a thin wash,
to give it a somewhat neutral color in harmony with to give it a somewhat neutral color in harmony with
that of the walls of the building in which it is to stand.

The back of the case should certainly be put on in the same way as the front, so that if it is ever desirabl to turn the case at right angles and have glass upon both ront and back, the back may be removed and a glas frame may be put on. If the back is to be solid woodwork which is perhaps desirable where heavy things are to be hung from it, care should be taken that it is built so that the expansion and contraction due to changes in the weather or the heating of the building may not strain weather or the heating of the building may not strain
the rest of the case. Perhaps as good a way as any would be to let the back of the case be a frame with compo board, as the compo board could be replaced at any time glass was desired. A diaphragm set back against th rear frame would serve for heavy objects and could be overed with burlap or print paper, as desired.

When the case has glass front and back, that is when the exhibit is to be viewed from two sides, or when it is not desirable to use the full depth of the case for the exhibition on hand, a diaphragm about $1 / 8$ of an inch shorter and narrower than the inside of the case may be inserted at any distance from the front of the case, and held in place either with round headed screws through the sides of the case or with small angle irons in front the diaphragm allows it to be adjusted or removed in a very few minutes with practically no waste and no unsightly scars which could not be retouched with putty and colored.

The cases should be made in uniform sizes or multiple sizes, like sectional book cases, so that they may be
moved about and re-assembled, for instance by placing two 3 foot cases side by side to harmonize with a 6 foo case, and so on, or by placing two cases 6 inches deep back to back to approximately harmonize with a case 1 foot deep. Cases should never be fastened to the walls in such a way that when they are moved the room is disfigured, requiring re-plastering or re-painting. A little forethought along these lines will save a large portion of the funds of museums which might be used
for other purposes instead of being thrown on the junk heap.

If it is desirable to let light in one or both ends of the case they may be made like the front and back, but then care must be taken that the frame is large enough to hold the screws necessary for supporting any shelves used. If a diaphragm is used, the screws to hold the rear corners of the shelves may be inserted in the diaphragm.

These general plans may be varied, the cases may be made of various heights, widths, and depths. They may be built with higher or lower bases and tops; or again, shorter cases may be built and placed upon tables or pedestals; cases may be super-imposed or hung upon a wall. Very large cases might be made on this same principal, by substituting frames with glass in place of the wooden sides of the cases, it being only necessary in such cases to carry the sides up and down from the top and bottom of the frame in the same manner that the front and back is carried up and down. If the case is so large, as for habitat groups, that it is necessary to have more than one frame, a mullion to which to screw the frames may be inserted between the top and bottom of the case where necessary, but this should not project beyond the sides of the frame. By this means the amount of wood exposed to view is kept at a minimum. If desired, a molding can be screwed over the crack where the frames meet, and if fastened to one of the frames that frame may be taken off first in opening and closing the case, which will save the trouble of unscrewing the molding.

One of the simple forms of these cases, 5 feet wide by 1 foot by 7 feet was made, with the exception of the frameand glass, by two carpenters, during the time which they could take from other work in a single day while

assisting in reorganizing the Rocky Mountains Park

The specifications which have been made by Mr. P. A. Taverner to accompany this description are for a somewhat more complicated and slightly more expensive case, and consequently a number of the dimensions and methods of construction are slightly different.

$$
\text { Material. }
$$

Lumber-All material in case to be of clear, white pine, whitewood or other material most readily obtainable in locality in clear lengths free from large or unsound knots or shakes.

All exposed work may be in oak or other wood to atch fittings already installed.

Sash-To be $13 / 8$ inch thick of common stock pattern-rails and styles 2 inches wide from glass to jamb, nd of sizes as shown.

Tops and Ends-May be of $7 / 8$ stuff with $3 / 8$ by $13 / 8$ inch rebate along sash jamb or may be built up of two thicknesses of $1 / 2$ inch stuff. The inner lining being nailed.

Diaphragm (to be supplied only where desired)-To be of $7 / 8$ inch stuff fastened together with flush end styles well nailed to prevent warping. All should be covered, both sides with burlap or other covering material or paneled according to decoration or other scheme of museum. Diaphragm to be held upright and in place by 1 inch by 1 inch by $1 / 8$ inch iron angles screwed to top and bottom of case on either side of diaphragm. For 3 -foot cases there should be two pair of such angles, top and bottom, and for 6-foot cases there should be three such pairs. Diaphragms may be moved to any situation in case by changing position of angles.

Shelves-Shelves for light specimens may be supported by screw eyes inserted in ends and diaphragm or mullions as indicated on drawings, turning them flatways and allowing them to project enough to engage shelves. For heavy specimens, iron brackets-stock sizes, or Shrosbree specimen hangers may be used whenever needed. If a coarse burlap is used over diaphragm, screws may be put in and removed as many times as necessar

Base or Mopboard-To be stock 6 inch base of whatever design may be desired and may be readily obtained at local lumber yard or mill.

Ends-All ends of cases to present perfectly flush surface, so that two or more cases may be butted together to appear as one case without unsightly or dustcatching spaces between.

Cases may be made in units of either 1 or 2 sash. A 1 sash case will then be just half the length of the 2 sash cases and will line up with them in series. The sashes are to be fastened in place by $21 / 2$ inch brass, round headed screws, driven through the sash into the frame behind. With this method neither locks or hinges are necessary, and all can be constructed by an ordinary carpenter without special joinery skill.

Glass-To be of sizes shown and of as good quality as procurable. The principal faults to be looked for being color, waves, bubbles or flaws.

\section{Scientific Exploration in Central Asia}

From Dr. F. de Filippi the Royal Geographical Society has received a report on the journey of scientific exploration which he has been carrying out between India and Central Asia, under the joint auspicies of the Italian and Indian governments. The expedition has lasted sixteen and a half months, and in that time has accomplished work of the highest scientific importance in Northern Kashmir and Southern Turkestan. The numerous staff included eminent Italian men ot science, as well as a party from the Survey of India.

From the point of view of geographical discovery the most interesting result has been the exploration of the eastern section of the giant Karakoram range. Here was found a glacier-named Remo-of unexpected size and importance. It is composed of three large rivers of ice, each about 20 miles in length and from 3 to 5 miles miles.

The expedition derives its chief importance, however, from the systematic scientific observations which were taken at a series of fourteen stations established between Srinagar and Kashgar. By means of these observations the gravimetric survey made by the Indian Survey Department in the plains of Hindustan has been joined on to the similar Russian survey in Russian Central Asia, and the whole has been connected with the gravimetric survey of Europe.

Regular meteorilogical and magnetic observations were also taken at the different stations. By arrangement with the Indian Meteorological Department, pilot balloons were sent ip simultaneously from the expedition's stations and from a number of the department' permanent stations; and by a comparison of the results it is hoped to obtain valuable information respecting the monsoon winds. - The London Daily Telegraph. 